\title{
HISTORY
}

\section{Great Ormond Street in 1941 and 1942}

\author{
J A Black
}

This is an account of my time as a resident student at the Hospital for Sick Children, Great Ormond Street, from the summer of 1941 until I qualified in June 1942.

The Hospital for Sick Children, founded by Dr Charles West in 1852, was the first children's hospital in the UK. During the second half of the 19th century children's hospitals were set up in other parts of London and in the major cities of England and Scotland, but Great Ormond Street has continued to be the largest, wealthiest, and most influential children's hospital in the country. Until recently, a post at Great Ormond Street was regarded as an essential part of the curriculum vitae of every aspiring paediatrician.

I entered University College Hospital (UCH) in September 1939, but my year was soon evacuated to the Welsh National School of Medicine in Cardiff, to escape the expected bombing of London. At it turned out, this was the time of the "phoney war" and London was not bombed. We returned in August 1940, in time for the "blitz". Anticipating a continuation of air raids, the medical school was moved to Leavesden Hospital in Abbots Langley for clinical teaching, and to Stanboroughs Hydro, in Garston, near Watford, for lectures and to accommodate the students. The Hydro continued to be run by the owners, the Seventh Day

Correspondence to: Dr Black

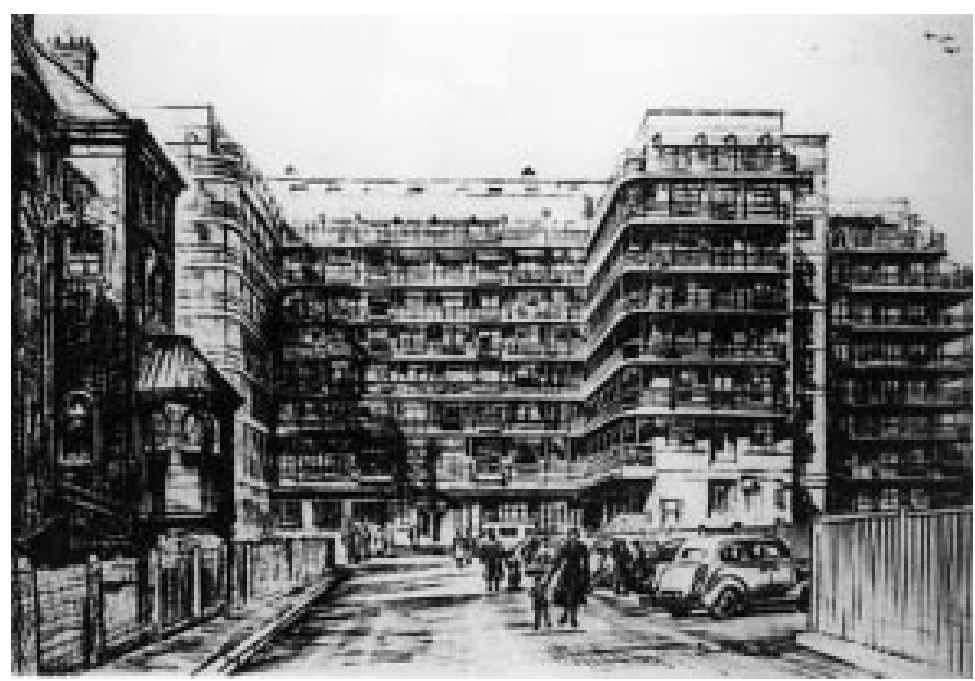

Figure 1 The Southwood building in 1945, from a drawing by Dennis Flanders. The chapel of the 1877 building, by Edward Barry, can be seen on the left of the picture. With permission of the museum and archives service, Great Ormond Street Hospital for Children NHS Trust.
Adventists, who favoured a strictly vegetarian diet, which was only slightly modified during the UCH occupation. For some curious reason, my intestinal tract failed to adapt to the high carbohydrate intake and produced an amount of gas that was physically uncomfortable and socially embarrassing.

I was therefore delighted to be asked, in the summer of 1941 , to join the team of UCH students resident at Great Ormond Street. In exchange for helping with air raid casualties (there were none during my period of residence) and conducting a weekly blood donor session, we were given free board and lodging and were allowed to attend the work of the hospital. Our other duty was to organise the Christmas show, which enabled us to lampoon the consultants and other staff in a series of comic sketches.

We lived on the top floor of the nurses' home, overlooking the remains of the bombed Indian students' hostel at the junction of Guilford Street and Grenville Street. We shared the nurses' sitting room (now the dining area) and had our meals in the doctors' dining room in the hospital. This was run by Ellen Dowling, a stout motherly Irish woman whose special care was her "boys", and by Lavinia Watson, a forthright young woman from Maltby in Yorkshire, who enjoyed teasing us about our posh accents. These two were more important to our welfare than anyone else in the hospital. At the evening meal we were each allowed a bottle of Tolly ale; it was a point of honour to flick off the bottle top with the handle of a fork, sending the top flying off at high speed. No one was ever injured but there were some narrow escapes. Another perk of living in the hospital was that some theatres, and Covent Garden in particular, used to send complimentary tickets to the nurses' home. In this way, we were able to see Margot Fonteyn and other famous stars of the ballet and opera. Another form of entertainment was to have a horsemeat steak in a café in Marchmont Street, about five minutes from the hospital.

Fortunately, the nurses' home was a modern building, completed in 1937, and the hospital block (fig 1) (later named the Southwood building in honour of Lord Southwood, Chairman of the Board of Management during the war years and proprietor of the "News Chronicle") had been finished in 1938; both were able to withstand all but the most severe bomb blast. 
However, in September 1940 a bomb hit the surgical block, damaging the west lift shaft, which remained unusable for the rest of the war. Shortly after this, another bomb broke a water main in Guilford Street and flooded the boiler room; an explosion was narrowly avoided as a result of the heroic efforts of 67 year old William Pendle, who received a George Medal. The old (1877) building remained largely undamaged, although until very recently bomb scars were visible in the brickwork on the Great Ormond Street frontage.

On 3rd September 1939 the Hospital had been designated a "casualty clearing station" (CCS) (all ages). Seventy five beds on the first floor were reserved for children, and outpatient clinics continued normally. Long stay patients were sent to Tadworth Court and Cuckfield Hospital in Surrey, and to the Emergency Medical Service (EMS) Base Hospital and the West Hertfordshire Hospital, both in Hemel Hempstead.

The medical officer in charge of the CCS was Dr Robert Frew, who had been appointed "physician to out patients" in 1919 and a full physician in 1926. He lived in the hospital with his wife and daughter Joan. I never discovered what he did but in 1936 he had written a textbook "Disease in childhood: a clinical study. The first year". " He described a condition "hyperphlebaemia" to which he attributed 43 unrelated conditions, ranging from cerebral haemorrhage to habit spasms, "genius", cretinism, coeliac disease, and asthma. In his introduction he wrote: "I propose to call it hyperphlebaemia, meaning an excessive quantity of blood forced into the intracorporeal circulation during birth before it is ready to receive it." Among the predisposing causes of hyperphlebaemia he considered breech delivery and dry labour as being the most important, although any abnormal delivery would suffice.

Having devoted 100 pages (about two thirds of the book) to the sequelae of hyperphlebaemia, he concluded: "Doubtless there will be additions to and deductions from my list, but it has served to show that here we have a great cause of disease, affecting different parts of the body and producing a bewildering array of clinical manifestations, but through them all runs the connecting thread of an unduly high percentage of 'abnormal births', and it is this fact that is of outstanding assistance in enabling us to make the diagnosis." He offered no treatment other than the avoidance of abnormal deliveries. Perhaps because of this aberration he was appointed "physician extraordinary" in June 1943; all other retired physicians were given the title of "consulting physician".

(Sir) Denis Browne (fig 2) was "surgeon in charge of surgical unit". A very tall man with a slight Australian accent, his height never seemed to overawe the children, with whom he was gentle and considerate. He was a brilliant surgeon, with an original and enquiring mind. $\mathrm{He}$ originated the use of controlled movement in the treatment of congenital dislocation of the hip, and treated talipes equinovarus by manipulation with his "beetle crusher", thus

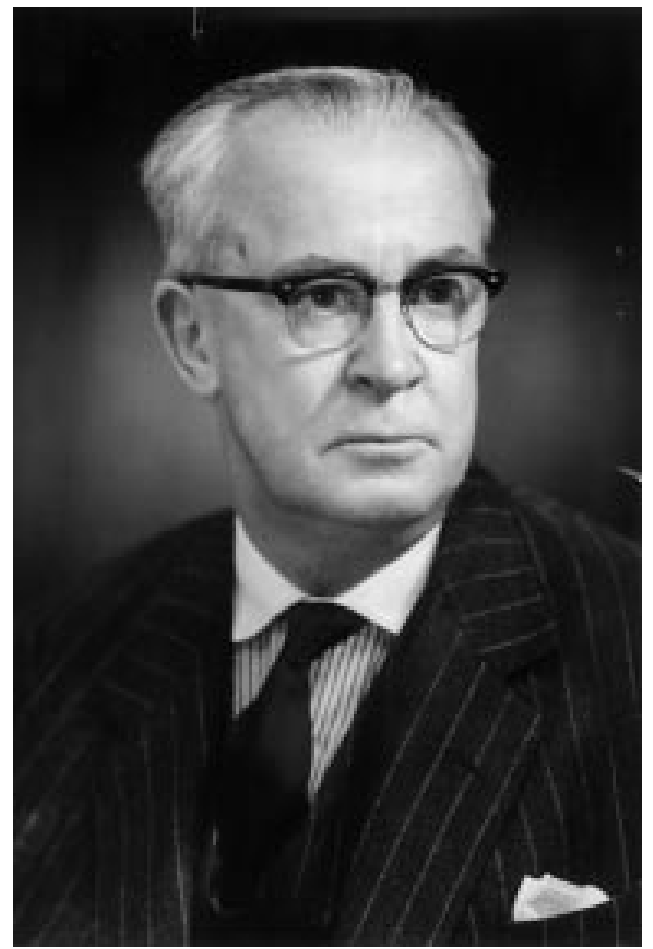

Figure 2 Sir Denis Browne in 1955. With permission of the museum and archives service, Great Ormond Street Hospital for Children NHS Trust.

retaining a mobile foot, in contrast to the orthodox treatment of open operation. He invented several surgical instruments, including a circular retractor holder, and was one of the first people to appreciate the importance of intrauterine compression and malposition as a cause of several congenital deformities.

The junior surgeon on the CCS team was Graham Humby. A romantic figure with floppy fair hair, he had trained as a plastic surgeon and invented the "Humby knife" for taking skin grafts. He was reputed to have been on the stage as a chorus boy before he took up medicine. Also on the staff of the CCS was an American paediatrician, Eleanor Peck, who was in charge of blood transfusion. Under the curious title "medical officers for general purposes" were Stefan Engel ("acting pathologist") and Dermod MacCarthy ("acting resident assistant physician"; RAP). Professor Engel, a short tubby man with a pink, bald pate, was a refugee from Austria. While doing a postmortem examination on a child with leukaemia, he remarked that children with leukaemia always had "such sad faces". Dermod MacCarthy, a quietly humorous man with bushy eyebrows, had a great love of children and a special interest in the gastroenteritis ward. In February 1942 Dermod joined the navy; when he appeared in the nurses' sitting room in his uniform as a surgeon lieutenant all the nurses swooned at his dashing appearance, while he smiled in a suitably modest manner. He was succeeded by Janet Gimson (later Roscoe). Dermod's predecessor as RAP, Dick Bonham Carter, worked in the headquarters of sector 4 of the EMS and lived in the hospital until he joined the Royal Army Medical Corps in 1942, serving with the First Airborne 
Division. From time to time he gave us informal seminars; he introduced me to the condition of paroxysmal sneezing as a manifestation of whooping cough in young children.

During the war years, the medical side of the hospital was staffed by five physicians: Donald Paterson, (Sir) Wilfrid Sheldon, (Sir) Alan Moncrieff, Reginald Lightwood, and Gifford Wyllie. Sheldon, an impressive, enigmatic man, had the unnerving habit of delaying his replies so long that one wondered whether he was going to respond at all: at that time he was driving a Wolseley car - the Rolls Royce came later. Curiously, Lightwood, a general paediatrician, was in charge of the "VD department". Gifford Wyllie was my favourite, a short man with a high domed forehead, he had an impish sense of humour. He was, I think, the first paediatrician to take a special interest in paediatric neurology, although he remained an excellent general paediatrician. At this time the only full physician was Donald Paterson, a Canadian, who wore a trilby hat on the back of his head and always seemed to be in a hurry.

Although not listed in the hospital reports of 1941 and 1942, David Nabarro was in charge of bacteriology, although his main interest was in congenital syphilis. I remember the enthusiasm with which he demonstrated the sabre tibiae of a child with late congenital syphilis, already a rare disease. Nabarro appears as bacteriologist in a group photograph taken in 1919, with Donald Paterson as house physician, Thomas Twistington Higgins as resident medical superintendent, and Norman Bethune, another Canadian, as house surgeon. Bethune later became famous for his work in China under Mao Tse Tung from January 1938 until his death from septicaemia in November 1939.

In 1941 Wilfrid Payne was already in post as biochemist, having been appointed in 1926. I did not get to know him and appreciate his great qualities until I worked in his department for a year in 1950. It was his work that provided the basis for the papers of Schlesinger, Lightwood, and others on hypercalcaemia and infantile renal acidosis during the early 1950s. A quiet man, he was underestimated for many years. He could not be pushed around; as he said, exaggerating his slight Sussex accent: "I won't be druv".

The visiting surgical staff consisted of Sir Lancelot Barrington-Ward (Chairman of the Medical Committee in 1941), who had been appointed surgeon in 1922; Eric Lloyd, an orthopaedic surgeon; Denis Browne ("DB"); and Thomas Twistington Higgins ("Twist"). $\mathrm{Mr}$ Higgins, whose main interest was in genito-urinary surgery, had a physicianly approach to his patients. I came to know him and appreciate his work when I became his house surgeon at the EMS Hospital in Hemel Hempstead in 1943. Sir Thomas Barlow, famous for his description of infantile scurvy and its relation to rickets, ${ }^{2}$ had been appointed to the staff in 1875 and was still a consulting physician to the hospital, although he no longer visited it. During the blitz in 1940, he was admitted for surgery, on his prostate, I think, to the private patients' wing at UCH. After a par- ticularly noisy night he remarked to his grandson, Andrew: "What a tempestuous night! The students have been very rowdy.". He died in 1945 at the age of 99 .

On the administration side, Herbert Rutherford was the house governor, assisted by NR Winwood. Dorothy Lane was the Matron; a small woman, she wore an elaborate lace cap precariously balanced on thinning grey hair. Dorothy Lane had a great presence and was held in awe and affection by the nurses.

Our main centres of teaching were at $\mathrm{UCH}$, Stanboroughs Hydro, and Leavesden Hospital. Fortunately, Peter Choyce, one of the student team, had a car with supplementary petrol coupons, in which he took us to and from Watford and Abbots Langley. At other times we attended the Great Ormond Street outpatient clinics, ward rounds, operations, postmortems, and other hospital activities. I only attended Donald Paterson's outpatients clinic once, when he reduced the mother of a child with Down's syndrome to tears by his insensitive approach. Nevertheless, Paterson was extremely influential politically in paediatrics. He founded the British Paediatric Association (BPA) in 1928 and was on the staff of the hospital from 1935 until his return to Canada in 1947. Shortly after the outbreak of war he prepared a paper for the BPA, ${ }^{3}$ which suggested that paediatric consultants should be appointed in all parts of the country to look after the health of evacuated children, to ensure continuity of treatment of chronic diseases and to prevent and control epidemic disease. Unfortunately, the idea did not appeal to the minister of health, Walter Elliott. Had it been implemented, it would have created a nation wide system of paediatric care years before the coming of the National Health Service.

Ward rounds at Great Ormond Street were formal affairs. Starting at 09:30 or 10:00 in the morning or at 14:00 in the afternoon, the consultant, accompanied by his registrar and houseman, combined the examination of his patients with informal discussion and teaching. Each consultant had his own methods of treatment and each ward had a different postoperative schedule for pyloric stenosis. At the end of the ward round the consultant and his retinue retired to sister's sitting room for coffee and biscuits or tea and cake.

Although the ward admission books for the early 1940 s are no longer available, the hospital admission books give a good indication of the type of cases admitted. For the months of June and July 1941, 55 medical cases were admitted. Meningitis (six) was the most frequent diagnosis, followed by pyloric stenosis (four), gastroenteritis (four), pulmonary tuberculosis (three), anaemia (three), pneumonia (three), infected scabies (three), marasmus (two), catarrhal jaundice (infective hepatitis) (two), and pink disease (two). An indication of the importance of the hospital as a tertiary referral centre even in the 1940s is shown by the admission of four cases of Wilms's tumour, which was treated by preoperative and postoperative deep $x$ ray at St Bartholomew's Hospital. 


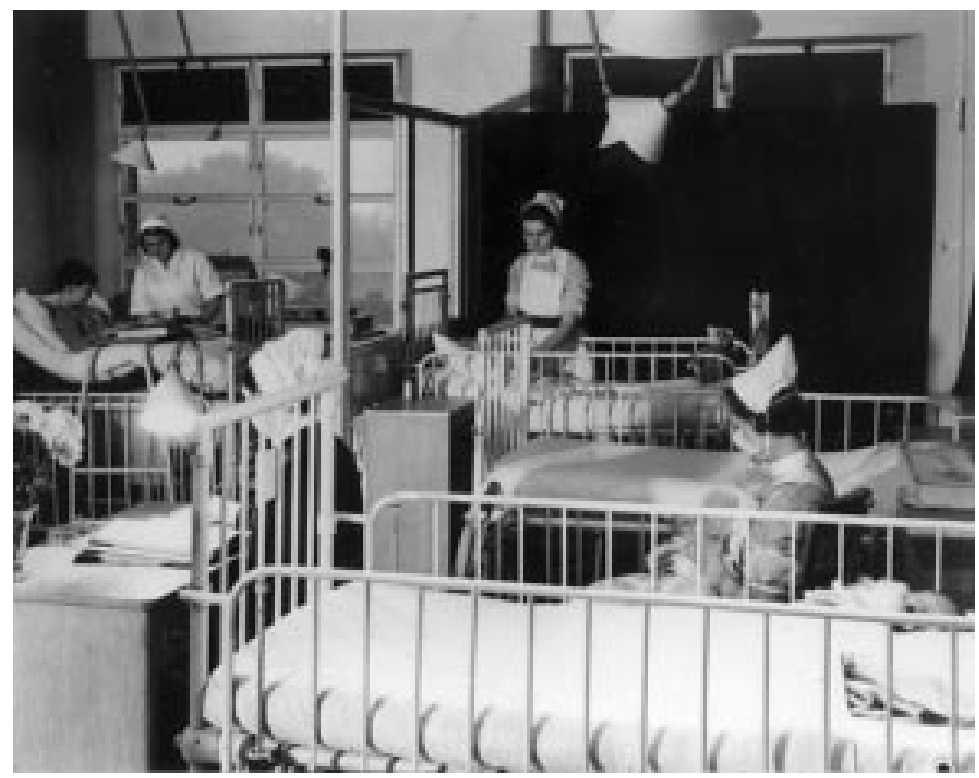

Figure 3 A typical ward in the 1940s. Dr Frew's daughter, foan, can be seen on the left of the picture. With permission of the museum and archives service, Great Ormond Street Hospital for Children NHS Trust.

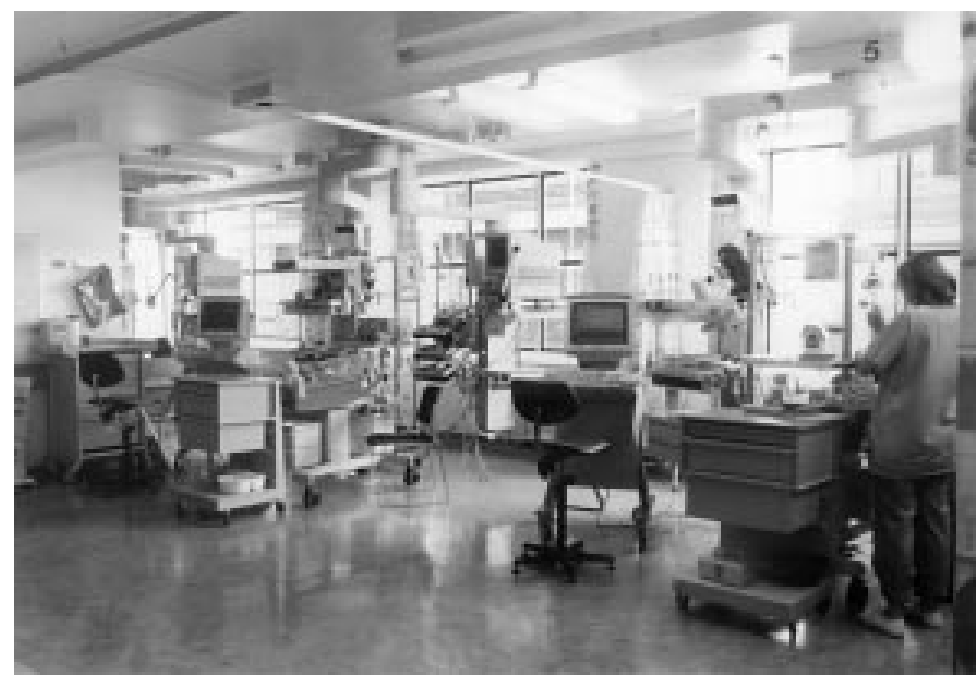

Figure 4 The intensive care unit in fune 1999. With permission of ICH Productions Ltd, department of medical illustration, Institute of Child Health.

Miliary tuberculosis and tuberculous meningitis were universally fatal; tuberculosis of the chest was treated with bed rest and tuberculous bone disease by immobilisation in plaster. There was, of course, no treatment for leukaemia. The only antibacterial agents available were sulphanilamide and sulphapyridine (" $\mathrm{M}$ \& B 693"), which were used for the treatment of pneumonia and meningitis and for the occasional case of "pyelitis" that failed to respond to "pot. cit". It was still taught that children with rheumatic carditis should be nursed lying flat, although that wise physician Max Rosenheim, at $\mathrm{UCH}$, was beginning to question this dogma. Gastroenteritis had a high mortality rate (there was a special cubiclised gastroenteritis ward, the other wards had four cubicles and six beds in an open ward (fig 3) (for com- parison fig 4 shows the intensive care unit today); severely dehydrated infants were treated with an intravenous drip of Hartman's solution, using a cut down and a Bateman's cannula. Children with infantile eczema were noted to undergo a temporary remission during an attack of gastroenteritis, presumably because milk and other foods were initially withheld. The most common minor operation was paracentesis of the tympanic membrane for otitis media and for some cases of gastroenteritis (the myth of "parenteral gastroenteritis" was still current); this resulted in the perforation of numerous slightly pink drums by unskilled house physicians. The aetiology of rhesus incompatibility was not yet understood, and I remember Janet Gimson showing me a bright yellow baby dying from kernicterus. It is of interest that Donald Paterson, in his textbook of paediatrics, ${ }^{4}$ written in 1941, advised the removal of septic tonsils and teeth to prevent the recurrence of "catarrhal jaundice".

My experience of paediatrics at Great Ormond Street was not typical of medical students. Each teaching hospital had a small paediatric department, rarely with more than 20 beds. The paediatric course was for six weeks, combined with other minor specialities such as ophthalmology, ENT, and dermatology. Care of the newborn was regarded as within the province of obstetricians, although they took little interest in the subject. My own experience at UCH left me with an impression of squalling infants, and of doctors and nurses unused to handling infants and children. It is scarcely surprising that at most medical schools, only two or three students each year became paediatricians.

The summer of 1942 was saddened by the death, from miliary tuberculosis, of Ieuan Davies, one of my particular friends on the student team. Ieuan, an ardent Welsh nationalist (he talked of "exporting goods to England"), died shortly after becoming engaged to one of the Great Ormond Street nurses.

My year at Great Ormond Street was indeed a formative one. Residence at Great Ormond Street, where children were treated with love and understanding, completely changed my attitude to the sick child, and I determined to return to paediatrics as soon as I could after my time in the army and to apply the hospital's motto: "the child first and always".

I am grateful for the help of $\mathrm{N}$ Baldwin (archivist), G Davies (patients' affairs manager), Great Ormond Street Hospital for Children NHS Trust, and J Clarke (librarian), Institute of Child Health. I have drawn on Great Ormond Street $1852-1952$ by T Twistington Higgins, London: Odhams Press, 1952, for some of the pre-1941 material.

1 Frew RS. Disease in childhood: a clinical study. The first year. London: Macmillan, 1936

2 Barlow T. The Bradshaw lecture on infantile scurvy and its relation to rickets. BMF 1894;ii:1029-34.

3 Cameron HC. The British Paediatric Association, 1928-1952. London: British Paediatric Association, 1955:31-5.

4 Paterson D. Sick children: diagnosis and treatment, 4th ed. Andover: Chapel River Press, 1941. 